\title{
Three Important Applications of Mathematics in Financial Mathematics
}

\author{
Xiaogang Yang \\ Chengdu Normal University, Chengdu, China \\ Email: 930761897@qq.com
}

How to cite this paper: Yang, X.G. (2017) Three Important Applications of Mathematics in Financial Mathematics. American Journal of Industrial and Business Management, 7, 1096-1100.

https://doi.org/10.4236/ajibm.2017.79077

Received: September 4, 2017

Accepted: September 22, 2017

Published: September 25, 2017

Copyright $\odot 2017$ by author and Scientific Research Publishing Inc. This work is licensed under the Creative Commons Attribution International License (CC BY 4.0).

http://creativecommons.org/licenses/by/4.0/

\begin{abstract}
This paper analyzes the basic connotation of financial mathematics, financial mathematics through research development, control theory, differential game theory and capital asset pricing model from stochastic optimal, and discusses three important applications of mathematics in the financial field.
\end{abstract}

\section{Keywords}

Financial Mathematics, Differential Game Theory, Asset Pricing, Stochastic Optimal Control Theory

\section{Introduction}

Financial mathematics is the product of applying mathematics to portfolio selection theory and option pricing theory. With the rapid development of the economic situation, the products and derivatives of the financial industry are constantly optimized and innovative, and new financial products and services are gradually increasing. The operation of financial markets, the design and pricing of financial derivatives, and the analysis and management of risk become very important, and the research and development of financial mathematics is becoming more and more important. Therefore, it is of practical significance to analyze the specific application of mathematics in the financial field.

\section{The Basic Connotation of Financial Mathematics}

Financial mathematics, also called analytical finance, mathematical finance and mathematical finance, is an interdisciplinary subject of mathematics and finance that arose in the late 1980s and early 90s. Financial mathematics mainly uses the modern mathematical theory and method (such as stochastic analysis, stochastic 
optimal control, portfolio analysis, nonlinear analysis, multivariate statistical analysis, mathematical programming, modern computational methods etc.) of financial (including banking, investment, bonds, funds, stocks, futures, options and other financial instruments and markets) analysis the number of theory and practice. The core problem is the selection theory of the optimal investment strategy and the asset pricing theory under the uncertain condition. Financial mathematics not only have a direct effect on the innovation of financial instruments and financial markets operate efficiently, but also for the company's investment decision-making and evaluation of project research and development (such as real options) and risk management in financial institutions has been widely used [1].

From a broad point of view, financial mathematics is a new discipline which applies mathematical theories and methods to the operation of Finance and economy. From the narrow perspective, mathematical problems in the financial field is mainly on the stock selection and portfolio analysis of asset pricing theory combined under conditions of uncertainty, which is the optimal arbitrage, and equilibrium theory the three most important basic concepts.

Applying mathematics to the financial field is based on some financial or economic assumptions, and uses abstract mathematical methods to construct mathematical models of how the financial mechanism works. Financial mathematics mainly includes the basic concepts and methods of mathematics, the related natural science methods and so on. They are applied in various forms of entry theory. The use of mathematics is to express, reason, and prove the underlying principles of finance. From the nature of financial mathematics, financial mathematics is an important branch of finance. Therefore, financial mathematics is completely based on the background and foundation of financial theory. The people who engage in financial mathematics through formal financial academic training will have more advantages in this context. Finance is used as a subdiscipline of economics of identity development, though it has a characteristic enough from the economic independence, but it still requires economic principle and economic technology related as background. At the same time, financial mathematics also needs financial knowledge, tax theory and accounting principles as the background of knowledge [2].

The theoretical basis of financial mathematics also includes mathematical modeling and statistical theory, the first step is a mathematical or statistical modeling, which is from the complex financial environment were key factors to identify related factors and independent factors, and then from a series of assumptions to deduce various relations, finally obtains the conclusion to make the conclusion explain. This modeling activity is not only very useful and very important, because in finance a small error, an error is derived, a wrong conclusion, or a conclusion of error explanation may lead to a financial disaster. In addition, in the study of financial mathematics, the application of computer technology also has a very prominent position. 


\section{Three Important Applications of Mathematics in Financial Mathematics}

\subsection{Differential Game Method}

In the modern financial theory, mathematics in the field of finance is another important application is analyzed in option pricing and investment decision using differential game method, and the application of this aspect has made remarkable achievements. Because the whole law of financial market does not accord with the hypothesis of steady state, the abnormal fluctuation of securities will lead to abnormal change in the process of abnormal fluctuation, and this kind of change will not obey the Brown motion. At this point, we need to use stochastic dynamic model to study and analyze the whole decision-making of securities investment. This method is not only in theory or in practice, but also has a great deviation. The financial problems and countermeasures by using the differential method to non geometry in the financial field of the Brown distribution has important use, not only can effectively relax this assumption can also be uncertain disturbances become hostile to the illusion of hand. The stability (robustness) of the strongest portfolio strategy can be obtained through the optimization analysis of the whole uncertain problem.

At the same time, in the process of entering the field of the analysis of the problem in using differential game method, only needs a Behrman equation, and this equation belongs to the first-order differential equation is two order partial differential equation to solve the problem of random in much simpler. So, the application of differential game method to study the problems in the financial sector will have broad prospects, especially has very important significance for the study of the random strategy, repeat, combination and other financial problems of securities investment.

Using differential game method to study option pricing problem and investment decision problem is an important direction of the development of modern financial theory, and some achievements have been achieved. When the financial market does not satisfy the steady-state assumption or abnormal fluctuations in stock prices, often do not obey the geometry Brown motion, then using the method of random dynamic model of securities investment decision problems both in theory, or in fact there is deviation from. Using the differential game method to study the financial decision problem can relax the hypothesis. The uncertainty disturbance is assumed to be a hostile one, and the optimal investment strategy with strong robustness can be obtained by optimizing the worst case. In addition, the Behrman equation for differential games is a first-order partial differential equation, which is much simpler than the two order partial differential equations for stochastic control problems. Therefore, the application of differential game method to the study of financial problems has broad application prospects.

\subsection{Capital Asset Pricing Model (CAPM)}

Markowitz (Markowitz, 1952) the dispersion of investment portfolio theory and 
efficiency for the first time as a means of rigorous mathematical tools to show a method for risk averse investors how to construct the optimal portfolio of risky assets in many. It should be said that this theory has a strong sense of normative, which tells investors how to make investment choices. But the problem is that in 1950s, even with the help of computer was just born, in practice the application of Markowitz theory is still hard work a tedious and boring; or, with the investment of the real world apart too seriously, thus it is difficult to be completely by investors-the United States Baumol of the Princeton University (William Baumol) said in his 1966 paper Tobin Markowitz system in this paper, according to Markowitz theory, even with the simplified model, to choose efficient portfolios from 1500 securities, the time for each run by a computer will cost $\$ 150-300$, but if you want to perform a complete Markovitz operation, the cost is at least 50 times the amount; and all of these must have a premise, is the analyst The expected return, risk, and correlation coefficients of the underlying securities must be sustained and accurate, otherwise the entire process will become meaningless. It is because of this problem, from the beginning of 1960s, SHARP (W. Sharpe, 1964), Linter (J. Lintner, 1965) and mossim (J. Mossin, 1966) as the representative of some economists began from the empirical point of view, to explore the reality of securities investment, namely Markowitz theory applied in reality can be if investors are using simplified? Markowitz portfolio theory to select the optimal portfolio, then the equilibrium prices of assets will be how to balance the return and risk in the form? Or, in the market equilibrium, asset price risk and how to determine?

The research of these scholars has directly led to the emergence of the capital asset pricing (CAPM) model. As one of the predictive model for risk assets based on expected profit equilibrium on the basis of CAPM, explains the formation of market equilibrium in investors by Markowitz's theory of investment management under the conditions of the theory of the relationship between the expected return and expected risk in a simple linear relationship between the expression of it, that there is a positive correlation the relationship between a beta scale an asset to the expected rate of return and measure the risk value of assets. It should be said that, as a kind of objective of risk asset equilibrium price decision theory, single index model, and based on CAPM not only simplifies the computation process of portfolio selection, the Markowitz portfolio selection theory in the real world a big step forward, but also makes the securities theory from the previous qualitative analysis to quantitative analysis, empirical turn from the normative, then the securities investment theory and practical operation, which has a great influence even to the development of financial theory and practice, has become the theoretical basis of modern finance.

Of course, in recent decades, as the focus of the capital market equilibrium model of attention, in the form of CAPM has been far beyond the traditional form, and put forward the SHARP Lintner Mossin, has made great progress, such as arbitrage pricing model, intertemporal capital asset pricing model, con- 
sumption capital asset pricing model, has formed a the system of capital market equilibrium theory [3].

\subsection{Stochastic Optimal Control Theory}

In the mathematical application of the current financial theory, another important application field is the use of mathematics to solve the stochastic problems in financial problems. The theory of stochastic optimal control is an important method and means to solve the financial problems with mathematical theory.

Stochastic optimal control is advanced in the development of the control theory gradually developed, through the application of Behrman principle in combination optimization, measure theory and functional analysis method of stochastic problem analysis. This method was formed in the late 60 s of the last century, and became mature gradually in the early 70s. From the application of stochastic optimal control theory, the response of financial experts in this field is very rapid. At the beginning of 70s, the finance research field which appeared a few articles related to economics papers, including Merton (Merton) are discussed using the method of continuous time consumption and portfolio, the portfolio analysis between them is more consistent with the actual situation; and Brock (Brock) and Millman (Mirman) in random changes, using discrete time method of optimal economic growth are discussed. Subsequently, the stochastic optimal control method has been applied in most financial fields.

\section{Epilogue}

This article, from the construction of differential game application, option pricing and investment decision in the capital asset pricing model and stochastic optimization theory to explore three aspects of the important application of mathematics in the field of finance, reflects the important role of mathematics in modern financial analysis.

\section{References}

[1] Tao, Y. and Zhang, Z.J. (2007) Application of Financial Mathematics in Modern Financial Theory. Group Economy Research, 34, 252.

[2] Zhou, X. (2010) Latest Theory and Modern Development of Financial Mathematics. Popular Business (Second Half), 2, 165.

[3] Lin, L. (2010) An Analysis of the Application of Mathematical Methods in the Financial Field. Finance and Economics (Academic), 10, 13. 
Submit or recommend next manuscript to SCIRP and we will provide best service for you:

Accepting pre-submission inquiries through Email, Facebook, LinkedIn, Twitter, etc. A wide selection of journals (inclusive of 9 subjects, more than 200 journals)

Providing 24-hour high-quality service

User-friendly online submission system

Fair and swift peer-review system

Efficient typesetting and proofreading procedure

Display of the result of downloads and visits, as well as the number of cited articles Maximum dissemination of your research work

Submit your manuscript at: http://papersubmission.scirp.org/

Or contact ajibm@scirp.org 